\title{
From over-stoichiometric to sub-stoichiometric enantioselective protonation with 2-sulfinyl alcohols: a view in perspective
}

\author{
Mercedes Medio-Simón, Pedro Alemán, Ana Cuenca, Jesús Gil, \\ Nuria Rodríguez, and Gregorio Asensio* \\ Departamento de Química Orgánica, Universidad de Valencia, Avda. V. A. Estelles s/n 46100 \\ Burjassot, Spain \\ E-mail: gregorio.asensio@uv.es
Dedicated to Professors José Elguero and Pedro Molina, two excellent chemists and friends, on the occasion of their $70^{\text {th }}$ and $60^{\text {th }}$ birthdays, respectively
(received 31 Dec 04; accepted 01 Apr 05; published on the web 08 Apr 05)

\begin{abstract}
A general study of the enantioselective protonation of prochiral enolates with 2-sulfinyl alcohols is reported. The modification of reaction conditions to reduce drastically the amount of chiral proton source needed to obtain a good enantiomeric excess is reported. The effects of the different factors controlling the stereoselectivity are clearly established. Different protocols for enolate generation are compared.
\end{abstract}

Keywords: Enolates, enantioselective protonation, sulfinyl alcohols

\section{Introduction}

Enantioselective protonation allows for the desymmetrization of prochiral enolates, which enables the preparation of optically active carbonyl compounds with a stereogenic carbon at the $\alpha$ - position. ${ }^{1}$ Several reports have described the synthesis of some important chemicals such as anti-inflammatory agents, ${ }^{1}$ fragrances ${ }^{2}$ and pheromones ${ }^{3}$ with this procedure. The methods used for enantioselective protonation that have been developed to date can be classified into two categories: (a) internal quench, ${ }^{3}$ where the protonating reagent is a chiral protic compound, and (b) external quench, ${ }^{4}$ where the proton source is an achiral protic compound coupled with a chiral additive/ligand. In both categories, several examples have been described in which the use of a stoichiometric amount or even an excess of the chiral compound makes it possible to obtain the corresponding chiral carbonyl derivatives with high ee. ${ }^{7}$ The first significant example of enolate enantioselective protonation was reported in 1978 by Duhamel and Plaquevent, ${ }^{8}$ but more intense research on the general scope of enantioselective protonation was conducted during 
the 1990's. During this period we started a systematic study on the enantioselective protonation of lithium ketone enolates with 2-sulfinyl alcohols (Scheme 1). In this paper we discuss the main conclusions derived from our experimental findings.
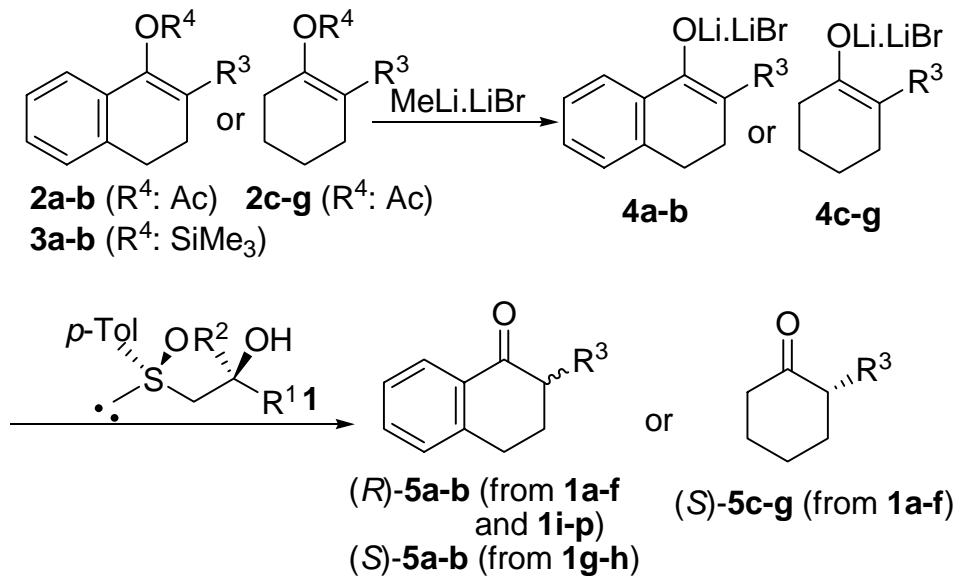

\begin{tabular}{|c|c|c|c|c|c|}
\hline \multicolumn{2}{|c|}{$\begin{array}{l}\text { (secondary } \\
\text { alcohols) }\end{array}$} & \multicolumn{2}{|l|}{$\begin{array}{l}\text { (tertiary } \\
\text { alcohols) }\end{array}$} & \multirow{2}{*}{\multicolumn{2}{|c|}{$2-5 R^{3}$}} \\
\hline $1 \mathrm{R}^{1}$ & $\mathrm{R}^{2}$ & $1 R^{1}$ & $R^{2}$ & & \\
\hline a $\mathrm{H}$ & $\mathrm{CF}_{3}$ & i $\mathrm{Ph}$ & $\mathrm{CF}_{3}$ & $\mathbf{a}$ & $\mathrm{CH}_{3}$ \\
\hline b $\mathrm{H}$ & $\mathrm{CClF}_{2}$ & j $\mathrm{CF}_{3}$ & $\mathrm{Ph}$ & b & $\mathrm{Bn}$ \\
\hline c $\mathrm{H}$ & $\mathrm{CHF}_{2}$ & k $\mathrm{Ph}$ & $i-\operatorname{Pr}$ & C & $\mathrm{C}_{6} \mathrm{H}_{5}$ \\
\hline d $\mathrm{H}$ & $\mathrm{CH}_{2} \overline{\mathrm{F}}$ & $\mathbf{I} \quad i-\mathrm{Pr}$ & $\mathrm{Ph}$ & d & $4-\mathrm{MeOC}_{6} \mathrm{H}_{4}$ \\
\hline e $\mathrm{H}$ & $\mathrm{CH}_{3}$ & $\mathbf{m ~ C H}$ & $\mathrm{CF}_{3}$ & e & $4-\mathrm{MeC}_{6} \mathrm{H}_{4}$ \\
\hline f $\mathrm{H}$ & $i-\mathrm{Pr}$ & $\mathbf{n} \mathrm{CF}_{3}$ & $\mathrm{CH}_{3}$ & $f$ & $4-\mathrm{Cl} \mathrm{C}{ }_{6} \mathrm{H}_{4}$ \\
\hline g $\mathrm{CF}_{3}$ & $\mathrm{H}$ & o $\mathrm{CH}_{3}$ & $\mathrm{CH}_{3}$ & $\mathbf{g}$ & $\mathrm{Bn}$ \\
\hline$i-\mathrm{Pr}$ & $\mathrm{H}$ & p $\mathrm{Ph}$ & $\mathrm{Ph}$ & & \\
\hline
\end{tabular}

Scheme 1. Internal quench with enantioselective protonation of lithium ketone enolates with 2sulfinyl alcohols.

\section{Stoichiometric enantioselective protonation: internal quench Generation of the enolate}

The first consideration in an enantioselective protonation reaction is the method used to generate the enolate. It is well known that enolate is a complex species that can be aggregated to a greater or lesser extent depending on the presence of additives or solvents that can be ligated to the metal. ${ }^{1 b}$ For example, the presence of amines must be avoided because amines can be ligands for the metal and can compete with the chiral proton source in the coordination and interfere with the desired proton-transfer process (for a more detailed explanation, see the paragraph entitled Criteria to Design the Chiral Proton Source). Thus, the method that is most frequently used for the generation of enolates, the use of amides for deprotonation of the parent ketone, is not a preferred method for the generation of enolates that will be subjected to protonation. Instead, the reaction of enolate precursors, such as silyl enol ether or enol acetates, with MeLi is more 
appropriate for this purpose, although the reaction of an organolithium reagent with esters also produces one equivalent of lithium alkoxide, which can affect subsequent protonation.

Halides are also additives that can change the enolate structure by favoring the deaggregation of oligomeric enolate aggregates (tetramers and dimers), leading to monomeric mixed aggregates.

In our initial reports, ${ }^{9,10}$ we described a dramatic example of the influence of additives in the enantioselective protonation of lithium ketone enolates with 2-sulfinyl alcohols. A high level of enantiofacial discrimination could be achieved only when the lithium enolate was generated in the presence of an equimolar amount of lithium bromide (Table 1, entries 2, 6, 8, 13, 17, and 19). Conversely, in the absence of lithium bromide (Table 1, entries 1, 3, 9, 12 and 18) or with only a sub-stoichiometric amount (Table 1, entries 4, 7, 10 and 14), the enantioselectivity was greatly reduced. In our procedure, lithium bromide was incorporated into the reaction by reacting the enolate precursor with a MeLi.LiBr complex. The lithium salt was only effective if it was present in the reaction medium before the generation of enolate. Addition of the lithium salt after generation of the enolate did not have a positive effect on the stereoselectivity (Table 1, entry 11).

The effect of the solvent on enantioselectivity has a similar origin as the effect discussed above for additives. While strongly coordinating solvents such as THF act as ligands for the metal, which impairs coordination of the proton source, non-coordinating solvents such as dichloromethane or toluene favor the formation of oligomeric aggregates. Weakly coordinating solvents such as diethyl ether can also be used because, while they minimize aggregation, they can also be easily displaced by a chiral alcohol. We observed this tendency in the reaction of 2sulfinyl alcohols with lithium ketone enolates. ${ }^{10}$ Poor enantioselectivity was achieved when enolate was generated in toluene as a solvent (Table 1, entry 16). The use of dimethyl ether gave better stereoselectivity (Table 1, entry 15). 
Table 1. Effects of lithium salts and solvents in the enantioselective protonation of enolates 4 with the 2-sulfinyl alcohols, 1

\begin{tabular}{|c|c|c|c|c|c|c|}
\hline Run & 1 & 2 & 3 & Lithium salts $^{\text {a }}$ & Solvent ${ }^{\mathrm{b}}$ time $^{\mathrm{c}}$ & $5 a(\%$ ee $)$ \\
\hline 1 & $\mathbf{a}$ & $\mathbf{a}$ & - & $\mathrm{LiCl}^{\mathrm{d}} \cdot \mathrm{Bu}^{\mathrm{t}} \mathrm{OLi}{ }^{\mathrm{e}}$ & $\mathrm{A}$ & \\
\hline 2 & $\mathbf{a}$ & $\mathbf{a}$ & - & $\mathrm{LiBr}^{\mathrm{f}} \cdot \mathrm{Bu}^{\mathrm{t}} \mathrm{OLi}{ }^{\mathrm{e}}$ & $\mathrm{A}$ & \\
\hline 3 & $\mathbf{a}$ & - & $\mathbf{a}$ & $\mathrm{LiCl}^{\mathrm{g}}$ & $\mathrm{A}$ & 59 \\
\hline 4 & $\mathbf{a}$ & - & $\mathbf{a}$ & $\mathrm{LiBr}^{\mathrm{h}}$ & A & 92 \\
\hline 5 & $\mathbf{a}$ & $\mathbf{a}$ & - & $\mathrm{LiCl}^{\mathrm{d}} \cdot \mathrm{Bu}^{\mathrm{t}} \mathrm{OLi}{ }^{\mathrm{e}}$ & B & 59 \\
\hline 6 & $\mathbf{b}$ & $\mathbf{a}$ & - & $\mathrm{LiBr}^{\mathrm{f}} \cdot \mathrm{Bu}^{\mathrm{t}} \mathrm{OLi}{ }^{\mathrm{e}}$ & A & 80 \\
\hline 7 & c & & $\mathbf{a}$ & $\mathrm{LiBr}^{\mathrm{h}}$ & $\mathrm{A}$ & 58 \\
\hline 8 & c & $\mathbf{a}$ & - & $\mathrm{LiBr}^{\mathrm{f}} \cdot \mathrm{Bu}^{\mathrm{t}} \mathrm{OLi}{ }^{\mathrm{e}}$ & A & 87 \\
\hline 9 & d & - & $\mathbf{a}$ & $\mathrm{LiCl}^{\mathrm{g}}$ & $\mathrm{A}$ & 83 \\
\hline 10 & d & - & $\mathbf{a}$ & $\mathrm{LiBr}^{\mathrm{h}}$ & $\mathrm{A}$ & 93 \\
\hline 11 & d & - & $\mathbf{a}$ & $\mathrm{LiBr}^{\mathrm{g}, \mathrm{i}}$ & $\mathrm{A}$ & 22 \\
\hline 12 & d & $\mathbf{a}$ & - & $\mathrm{LiCl}^{\mathrm{d}} \cdot \mathrm{Bu}^{\mathrm{t}} \mathrm{OLi}{ }^{\mathrm{e}}$ & A & 66 \\
\hline 13 & d & $\mathbf{a}$ & - & $\mathrm{LiBr}^{\mathrm{f}} \cdot \mathrm{Bu}^{\mathrm{t}} \mathrm{OLi}{ }^{\mathrm{e}}$ & $\mathrm{A}$ & 67 \\
\hline 14 & e & - & $\mathbf{a}$ & $\mathrm{LiBr}^{\mathrm{h}}$ & A & 22 \\
\hline 15 & e & - & $\mathbf{a}$ & $\mathrm{LiBr}^{\mathrm{h}}$ & B & 83 \\
\hline 16 & e & - & $\mathbf{a}$ & $\mathrm{LiBr}^{\mathrm{h}}$ & $\mathrm{C}$ & 58 \\
\hline 17 & e & $\mathbf{a}$ & - & $\mathrm{LiBr}^{\mathrm{f}} \cdot \mathrm{Bu}^{\mathrm{t}} \mathrm{OLi}{ }^{\mathrm{e}}$ & $\mathrm{A}$ & 55 \\
\hline 18 & $\mathbf{f}$ & $\mathbf{a}$ & - & $\mathrm{LiCl}^{\mathrm{d}} \cdot \mathrm{Bu}^{\mathrm{t}} \mathrm{OLi}{ }^{\mathrm{e}}$ & A & 36 \\
\hline \multirow[t]{3}{*}{19} & $\mathbf{f}$ & $\mathbf{a}$ & - & $\mathrm{LiBr}^{\mathrm{f}} \cdot \mathrm{Bu}^{\mathrm{t}} \mathrm{OLi}{ }^{\mathrm{e}}$ & A & 85 \\
\hline & & & & & & 54 \\
\hline & & & & & & 90 \\
\hline
\end{tabular}

${ }^{a}$ Equivalents of lithium salt /equivalents of enolate 4. ${ }^{\mathrm{b}} \mathrm{A}: \mathrm{CH} 2 \mathrm{Cl} 2 ; \mathrm{B}: \mathrm{CH} 2 \mathrm{Cl} 2$ :Et2O (1:1); C: Toluene. ${ }^{\mathrm{c}}$ Reaction time $1.5 \mathrm{~h} .{ }^{\mathrm{d}} 0.146 .{ }^{\mathrm{e}} 1.0 .{ }^{\mathrm{f}} 1.46 .{ }^{\mathrm{g}} 0.073 .{ }^{\mathrm{h}} 0.73 .{ }^{\mathrm{i}} \mathrm{LiBr}(1.2 \mathrm{eq})$ added to preformed enolate.

\section{Criteria for designing the chiral proton source}

The chiral protonating reagent is a key component in internal quench enantioselective protonation. Since asymmetric protonation requires that proton transfer occurs under a kinetically controlled process, the proton donor must be moderately acidic, otherwise the proton is transferred by diffusion, which makes it difficult to discriminate between the two diastereomeric transition states. In the search for an efficient chiral protonating agent, the following criteria might be useful. ${ }^{1 b}$ Ideally, the chiral proton source should be a weak acid to allow better discrimination between transition states. It should also contain electron-rich groups capable of undergoing chelation, which may enhance the conformational rigidity in the transition state. Optimally, the transferred proton should be located near the stereogenic center (within the chiral environment). Finally, the chiral proton source should be readily accessible in both 
enantiomeric forms and easily recoverable. These criteria are satisfied by 2-sulfinyl alcohols. Indeed, they can be easily prepared in a homochiral pure form and can achieve conformational rigidity through chelation of the sulfinyl group to the metal.

\section{Effect of the amount of the chiral proton source: over-stoichiometric reaction}

The enantioselective protonation of any lithium ketone enolate with any sulfinyl alcohol always required an over-stoichiometric amount (2.5-3 eq) of the chiral proton source to achieve the highest enantioselectivity. When a stoichiometric amount of the sulfinyl alcohol was used, a noticeable decline in asymmetric induction was observed. ${ }^{11}$ If enol acetates are used as enolate precursors, the requirement for a over-stoichiometric amount of sulfinyl alcohol can be ascribed to the presence of an additional base equivalent, since an equivalent of lithium tert-butoxide is generated in the reaction medium together with enolate. However, when silyl enol ether was used as an enolate precursor, an over-stoichiometric amount of chiral alcohol was still required, although in this case no additional base was generated in the medium. ${ }^{11}$ Thus, the need for additional amounts of sulfinyl alcohol may be associated with reversible proton transfer and /or competitive O-protonation of the enolate. ${ }^{1 \mathrm{~b}}$

\section{Effect of changes in the structure of the chiral proton source}

With regard to the number of stereogenic centers, 2-sulfinyl alcohols can be classified into two groups: a) those with two stereogenic centers: the sulfur atom and the carbon attached to the hydroxy function (1a-n), and b) those in which sulfur is the only stereogenic atom (10-p). Sulfinyl alcohols 1o-p (Table 2, entries 15 and 16) were poor chiral proton sources for the enantioselective protonation of lithium enolates, independent of the types of substituents bound to the sulfur or the carbon. ${ }^{11}$ The poor asymmetric induction detected for sulfinyl alcohols 10-p may be related to the fact that the delivered proton is not located near the stereogenic center. On the other hand, sulfinyl alcohols 1a-n showed variable efficacy depending on the configuration at the stereogenic carbon atom and the types of substituents bound to this carbon. Sulfinyl alcohols 1a-f in which the alcohol was secondary and which had an $(S, R s)$ configuration at the stereogenic centers were found to be powerful protonating agents (Table 2, entries $1-6)^{10}$ For these alcohols, a variation in the substituent bound to the stereogenic carbon only slightly affected the stereoselectivity. On the other hand, with the diastereomeric 2-sulfinyl alcohols $(R$, $R s)-1 g-\mathbf{h}$, a change in the substituent was associated with noticeable changes in enantioselectivity. $(R, R s)-\mathbf{1 g}-\mathbf{h}$ sulfinyl alcohols were less effective than their corresponding diastereomers (Table 2, compare entries 2 and 6 with entries 7 and 8) and more importantly, the sense of induction was opposite (Table 2, entries 7 and 8). The change in the sense of induction with a change in the configuration at the stereogenic carbon in the diastereomeric alcohols together with the low stereoselection observed with alcohols 10-p suggests that this may play a major control in the stereoselection for the stereogenic carbon. However, a suppression of the chirality at the sulfur atom by conversion of the sulfinyl group to sulfone reflected a strong 
decrease in asymmetric induction. ${ }^{12}$ The two stereogenic atoms appear to be indispensable for achieving the proper control of enantiofacial discrimination.

Table 2. Effects of the structure of the sulfinyl alcohol in the enantioselectivity

\begin{tabular}{cccc}
\hline Run & & $\mathbf{1}$ & $(\%$ ee $) \mathbf{5 a}^{\mathrm{a}}$ \\
\hline 1 & A & $\mathbf{a}$ & 92 \\
2 & A & $\mathbf{b}$ & 87 \\
3 & & $\mathbf{c}$ & 93 \\
4 & Secondary & $\mathbf{d}$ & 83 \\
5 & alcohols & $\mathbf{e}$ & 85 \\
6 & A & $\mathbf{f}$ & 90 \\
7 & & $\mathbf{g}$ & $88^{\mathrm{b}}$ \\
8 & A & $\mathbf{h}$ & $60^{\mathrm{b}}$ \\
9 & - & $\mathbf{i}$ & 75 \\
10 & - & $\mathbf{j}$ & 23 \\
11 & - & $\mathbf{k}$ & 53 \\
12 & Tertiary & $\mathbf{I}$ & 12 \\
13 & alcohols & $\mathbf{m}$ & 17 \\
14 & - & $\mathbf{n}$ & 4 \\
15 & - & $\mathbf{0}$ & 5 \\
16 & A & $\mathbf{p}$ & 40 \\
\hline
\end{tabular}

${ }^{\mathrm{a}}$ Configuration $(R)$ otherwise noted. ${ }^{\mathrm{b}}$ Configuration $(S)$.

The behavior of the tertiary 2-sulfinyl alcohols 1i-n differed from that seen for the secondary alcohol series. In contrast to the results detected for the diastereomers of secondary sulfinyl alcohols, no change in the sense of induction was observed with diastereomeric tertiary alcohols (Table 2, entries 9-14). There was also a difference in the control of enantioselectivity exercised by structurally different $\mathrm{R}^{1}$ and $\mathrm{R}^{2}$ groups bound to the stereogenic carbon, since in the tertiary alcohols structural variations in these groups produced major changes in enantiofacial discrimination. The more efficient tertiary sulfinyl alcohols were those that had an aryl group as an $\mathrm{R}^{2}$ substituent (Table 2, entries 9 and 11).

In general, the effects of substituents $\mathrm{R}^{1}$ and $\mathrm{R}^{2}$ on the enantiofacial discrimination of 2sulfinyl alcohols 1a-p can be explained by assuming that protonation with sulfinyl alcohols is governed by complexation with the lithium enolate (for a more detailed explanation, see the paragraph devoted to the mechanism of the reaction). The structure of the substituents can affect the conformer populations, favoring or disfavoring the conformation of the sulfinyl alcohol required in the transition state for proton transfer. ${ }^{12}$ 


\section{Effects of temperature and the acidity of the proton source}

The reaction temperature affected the enantioselectivity differently depending on the 2-sulfinyl alcohol used in protonation. For the more acidic perfluorinated alcohols $\mathbf{1 a}-\mathbf{b}$, a higher enantioselectivity in the protonation of the lithium enolate 4a was achieved when the reaction was carried out at low temperature (Table 3, entries 1 and 3). ${ }^{10}$ In contrast, difluorinated alcohol 1c showed unique behavior. Enantioselective protonation at $-78^{\circ} \mathrm{C}$ over $1.5 \mathrm{~h}$ gave the highest e.e. (Table 3, entry 5). An unexpected result was obtained when the reaction was performed below $-78^{\circ} \mathrm{C}$ : the e.e. decreased when the reaction was conducted at $-100{ }^{\circ} \mathrm{C}$ for $1.5 \mathrm{~h}$ (Table 3 , entry 6). From the previous results with perfluorinated 2-sulfinyl alcohols $1 \mathbf{1 a}-\mathbf{b}$ at -78 and $100^{\circ} \mathrm{C}$, there appears to be a relation between the acidity and the optimal reaction temperature, since the more acidic alcohols appear to have an optimal temperature of $-100^{\circ} \mathrm{C}$ (Table 3 , entries 1 and 3), whereas the less-acidic alcohols have an optimal temperature of $-78^{\circ} \mathrm{C}$ (Table 3 , entry 5). This hypothesis strongly suggests that the decrease in e.e. observed at $-100^{\circ} \mathrm{C}$ with $1 \mathrm{c}$ might be related to a slower rate constant for proton transfer. However, further experiments to explore this possibility gave contradictory results. Indeed, the e.e. decreased further when the reaction time was doubled ( $3 \mathrm{~h}$ ) (Table 3, entry 7), although an opposite trend would be expected if a slow rate of proton transfer is related to a decrease in stereoselectivity. In addition, stereoselectivity was not improved by changing the temperature profile up to the aqueous quenching step, which shows that protonation occurs at low temperature (Table 3, entry 8). In contrast, alcohols $\mathbf{1 d}$ and 1e showed the expected behavior. They gave similar e.e. values at both temperatures (Table 3 , entries 9-14), and no improvement was observed when the reaction was performed at $-60^{\circ} \mathrm{C}$ with e alcohol 1d (Table 3, entry 12). However, the behavior of non-fluorinated alcohol 1f (Table 3, entries 16-24) was similar to that described for alcohol 1c. ${ }^{13}$ In the case of alcohol 1f, the greatest enantioselectivity was attained at $-50^{\circ} \mathrm{C}$ (Table 3, entries 19 and 23). No further increase in the degree of asymmetric induction was achieved with minor changes around this temperature (Table 3, entries 18, 20, and 24). 
Table 3. Effects of the temperature and the acidity of the 2-sulfinyl alcohols in the enantioselectivity

\begin{tabular}{|c|c|c|c|}
\hline Run & 1 & $\left(\mathrm{~T}^{\circ} \mathrm{C}\right)(\text { time })^{\mathrm{a}}$ & $\% \mathrm{ee}^{\mathrm{b}}$ \\
\hline 1 & $\begin{array}{l}\mathbf{a} \\
\mathbf{b} \\
\mathbf{d}\end{array}$ & -100 & 92 \\
\hline 2 & $\begin{array}{l}\mathbf{b} \\
\mathbf{b} \\
\mathbf{d}\end{array}$ & -78 & 71 \\
\hline 3 & $\begin{array}{l}\mathbf{b} \\
\mathbf{b} \\
\mathbf{d}\end{array}$ & -100 & 87 \\
\hline 4 & $\begin{array}{l}\mathbf{b} \\
\mathbf{b} \\
\mathbf{d}\end{array}$ & $-100(3 h)$ & 85 \\
\hline 5 & $\begin{array}{l}\text { c } \\
\text { b } \\
\text { d }\end{array}$ & -78 & 93 \\
\hline 6 & $\begin{array}{l}\text { c } \\
\text { b } \\
\text { d }\end{array}$ & -100 & 87 \\
\hline 7 & $\begin{array}{l}\text { c } \\
\text { b } \\
\text { d }\end{array}$ & $-100(3 \mathrm{~h})$ & 40 \\
\hline 8 & $\begin{array}{l}\mathbf{c} \\
\mathbf{b} \\
\mathbf{d}\end{array}$ & $-100^{1}$ & 46 \\
\hline 9 & $\begin{array}{l}\text { d } \\
\mathbf{b} \\
\mathbf{d}\end{array}$ & -78 & 83 \\
\hline 10 & $\begin{array}{l}\text { d } \\
\mathbf{b} \\
\text { d }\end{array}$ & $-78(3 h)$ & 81 \\
\hline 11 & $\begin{array}{l}\text { d } \\
\mathbf{b} \\
\mathbf{d}\end{array}$ & -100 & 82 \\
\hline 12 & $\begin{array}{l}\mathbf{d} \\
\mathbf{b} \\
\mathbf{d}\end{array}$ & -60 & 80 \\
\hline
\end{tabular}


Table 3. Continued

\begin{tabular}{llll}
\hline 13 & d & -78 & 82 \\
& $\mathbf{b}$ & & \\
$\mathbf{h}$ & $\mathbf{e}$ & -78 & 80 \\
& $\mathbf{b}$ & & \\
& $\mathbf{d}$ & & \\
15 & $\mathbf{e}$ & -100 & \\
& $\mathbf{b}$ & & \\
16 & $\mathbf{d}$ & & 85 \\
17 & $\mathbf{f}$ & -100 & 85 \\
18 & $\mathbf{f}$ & -78 & 83 \\
19 & $\mathbf{f}$ & -65 & 90 \\
20 & $\mathbf{f}$ & -50 & 87 \\
21 & $\mathbf{f}$ & -40 & $76^{\mathrm{c}}$ \\
22 & $\mathbf{f}$ & -100 & $76^{\mathrm{c}}$ \\
23 & f & -78 & $84^{\mathrm{c}}$ \\
24 & f & -50 & $87^{\mathrm{c}}$ \\
\hline
\end{tabular}

${ }^{\mathrm{a}}$ Reaction time $1.5 \mathrm{~h}$ otherwise noted, ${ }^{\mathrm{b}}$ ketone $\mathbf{5 a}$ otherwise noted; ${ }^{\mathrm{c}}$ Ketone $\mathbf{5 b}$.

To account for the facts above, it is worth considering that temperature, in addition to the rate of proton transfer, can strongly affect other aspects of the reaction. Thus, the enolates occur in solution as monomeric ion pairs and their pure or mixed aggregates, which equilibrate slowly depending on the temperature and solvent. Therefore, the protonation reaction may result in different stereoselectivities for each of the aggregates. In addition, 2-sulfinyl alcohols $\mathbf{1}$ are weak proton donors, and the direct protonation of the enolate by (solvated) protons is unlikely. In this case, the proton source and substrate should assemble before the proton and the enolate metal are exchanged (more or less simultaneously) between the two reactants. Thus, for a given temperature and proton source, stereoselectivity is the complex result of several factors that might reflect the composition of the mixture formed by the enolate as an ion pair, pure-aggregate or mixed-aggregate, and the rate of the assembly of each type of enolate with the proton source. ${ }^{10,13}$ The increase in enantioselectivity with an increase in the temperature of protonation observed with alcohols $\mathbf{1 c}$ and $\mathbf{1 f}$ is not common in the field of enantioselective protonation. In fact, there is only one additional example in the literature concerning the protonation of a silyl enol ether by mandelic acid bound to a polymeric resin. ${ }^{14}$ The authors of that report explained their result on the basis of a two-step mechanism involving the preliminary formation of rapidly interconverting diastereomeric complexes. However, the e.e. values obtained at different temperatures do not fit the Eyring plot. Therefore, these results cannot be explained solely by a 
change in the dominance of enthalpy and entropy in intermediate steps. Due to the complex structure of the enolate, we suppose that although an iso-selective temperature may exist, it might be difficult to demonstrate using realistic kinetic data.

\section{Synthesis of chiral cyclohexanols by enantioselective protonation}

After we developed an appropriate methodology for obtaining chiral ketones with high facial enantioselectivity, we planned to use this reaction to prepare fine chemicals. We selected chiral cyclohexanols because, among the chiral auxiliaries, they are versatile and offer high levels of stereocontrol. Our method involved the enantioselective protonation of 2-aryl cyclohexanone enolate 4c-g with 2-sulfinyl alcohols 1a and 1f, followed by diastereoselective reduction of the corresponding ketone. $^{7 \mathrm{e}, 15}$ To perform the diastereoselective reduction, we developed a new procedure based on the use of sodium naphthalenide in the presence of a proton source. An important feature of our method compared to the alternative asymmetric synthesis of chiral cyclohexanols is that the chiral reagent used, sulfinyl alcohol, is almost completely recovered and is available from menthol, an inexpensive chiral source. Enantioselective protonation gave excellent results with a series of aryl cyclohexanones 5c-g (90-99\% ee). Enantioselective protonation is the most accurate method for obtaining chiral $\alpha$-aryl ketones since the alternative procedure, palladium-catalyzed arylation of the parent ketone, does not allow us to obtain a homochiral carbonyl compound with a tertiary stereogenic center at the $\alpha$ position because of racemization of the aryl ketone due to the strong basic medium required in the reaction. Conversely, the reduction process gave good results only when the aryl was unsubstituted or substituted with an electron donor group, otherwise important side reactions occurred.

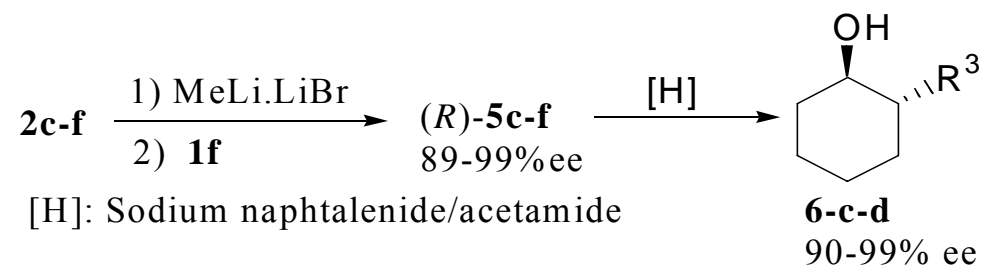

Scheme 2. Preparation of aryl cyclohexanol by enantioselective protonation/ diastereoselective reduction sequence.

\section{Study of the molecular mechanism of the proton transfer process}

Although enantioselective protonation has been the subject of systematic research over the past decade, only a few reports have addressed mechanistic issues. The lack of information on this topic may be related to the difficulty of obtaining realistic information on the global enolate structure in the transition state. Despite these limitations, we thought it could be useful to gain 
insight into the mechanism of the reaction with 2-sulfinyl alcohols by performing a theoretical study on the molecular mechanism.

To understand the mechanism of these enantioselective protonations, and the role of lithium bromide in the reaction pathway, the molecular process associated with proton transfer was studied using quantum mechanical procedures at the PM3 semi-empirical level. ${ }^{10}$ The energy profiles for the two pathways, with proton transfer considered to be an intramolecular process, are shown in Figure 1. The geometries of the transition structures (TS), including selected geometrical parameters, are shown in Figure 2. The heats of formation for the stationary points are shown in Table 4.

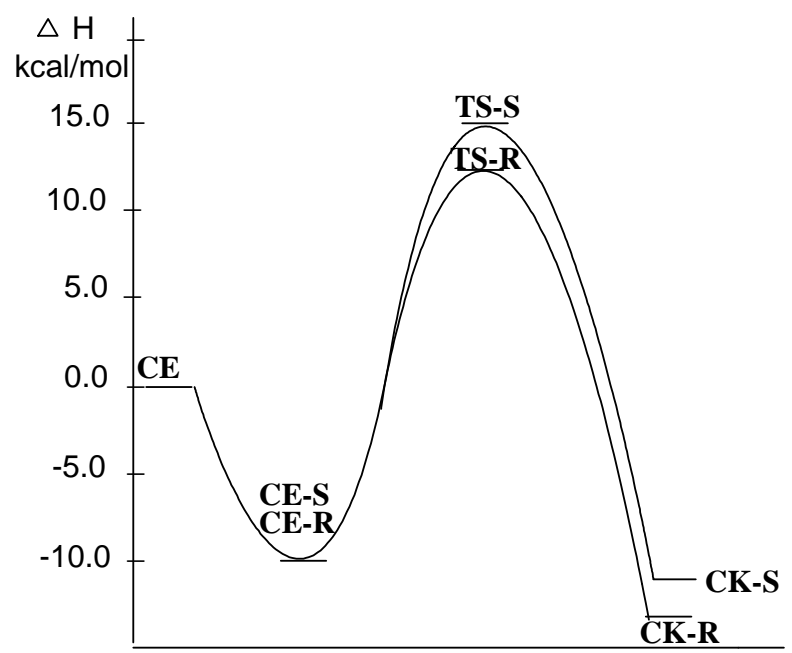

Figure 1. Energy profiles for intramolecular proton transfer between $\mathbf{1}$ and $\mathbf{4}$ in the presence of $\mathrm{LiBr}$.

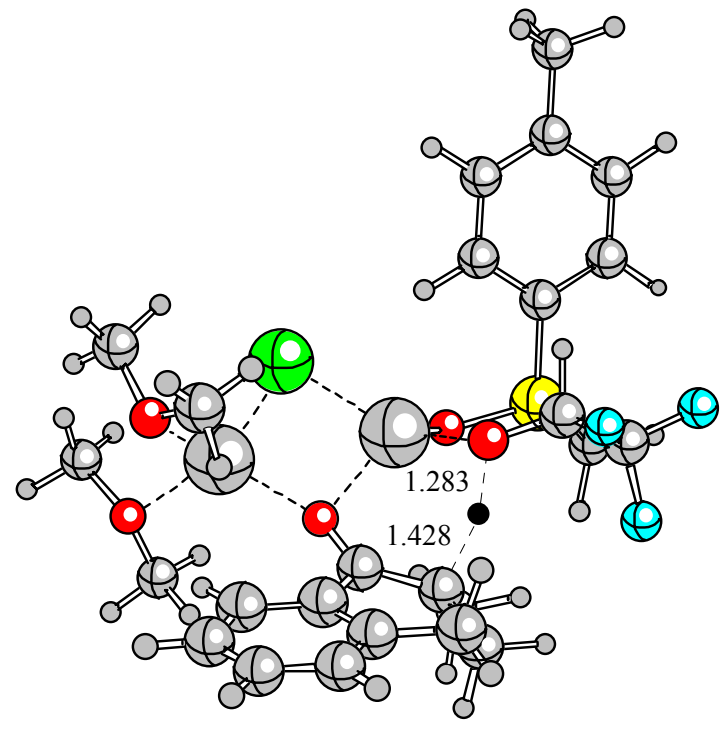

TS-R

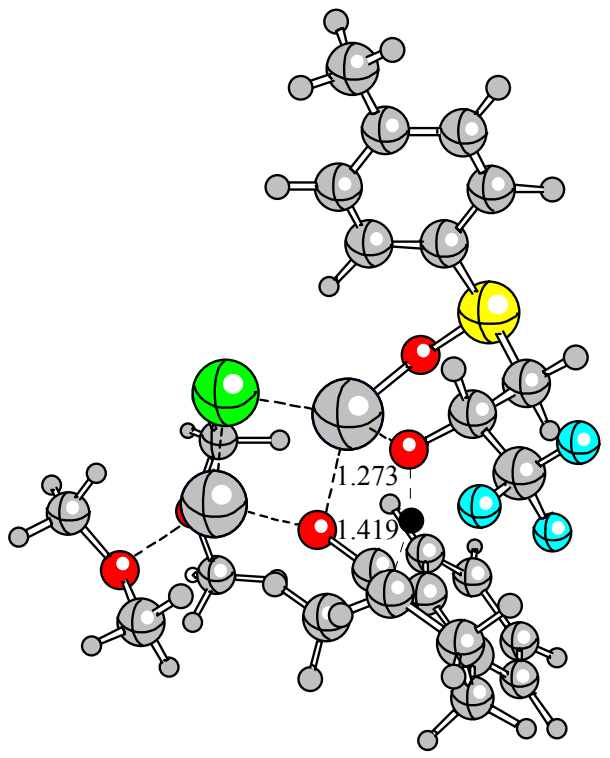

TS-S

Figure 2. PM3 geometries and selected geometric parameters $(\AA)$ for the transition structures TS-R and TS-S. 
Table 4. Heat of formation $(\mathrm{kcal} / \mathrm{mol})$ of the stationary points in intramolecular proton transfer for the reaction between 2 and 5 in the presence of $\mathrm{LiBr}$

\begin{tabular}{cccccc}
\hline CE-R & CE-S & TS-R & TS-S & CK-R & CK-S \\
\hline-442.44 & -442.37 & -420.59 & -416.68 & -444.87 & -443.29 \\
\hline
\end{tabular}

First, we considered the existence of a mixed dimer arising from lithium enolate and lithium bromide. Based on data in the literature ${ }^{16}$ we determined that the mixed dimer existed as a fourmembered ring where the bromide anion and the oxygen atom of the enolate are connected by two lithium cations. These bridging cations are in an approximately tetrahedral environment provided by two pairs of oxygen atoms corresponding to two molecules of dimethyl ether. The solvent used for empirical generation of the enolate was diethyl ether. However, the ethyl groups were replaced by methyl to simplify the calculations. Subsequent substitution of the solvent molecules of one lithium atom for chiral alcohol 1 gives two enolate complexes, CE-R and CE$\mathbf{S}$, which may be considered precursors to the corresponding transition structures. These species represent minima in the corresponding reaction pathways, as shown in Figure 1. Finally, CE-R and $\mathbf{C E}-\mathbf{S}$ can be converted to two chiral complexed ketones $\mathbf{C K}-\mathbf{R}$ and $\mathbf{C K}-\mathbf{S}$, via the transition structures TS-R and TS-S, respectively.

The di-lithium transition structures TS-R and TS-S can be described as six-membered rings in which proton transfer takes place via a favorable intramolecular pathway. In contrast to the very similar energy values calculated for the mono-lithium TS, ${ }^{9}$ transition structure $\mathbf{T S}-\mathbf{R}$ is 3.9 $\mathrm{kcal} / \mathrm{mol}$ less energetic than TS-S, which agrees well with the experimental results. The lengths of the breaking $\mathrm{O}-\mathrm{Ht}$ and forming $\mathrm{C}-\mathrm{Ht}$ bonds in TS-R are 1.283 and $1.428 \AA$, respectively, whereas those in TS-S are shorter, at 1.273 and $1.419 \AA$, respectively. These geometric values are close to those in mono-lithium TSs, which shows that the geometry does not change with a change in the lithium aggregate state. Normal-mode analysis of these TSs gave only one imaginary frequency in each case (1950.2i and $1931.1 \mathrm{i} \mathrm{cm}-1$ for TS-R and TS-S, respectively). The relatively high values of these imaginary frequencies reflect the fact that the migrating proton is not coupled with the motion of heavy atoms. ${ }^{16}$ These imaginary frequencies are higher than those calculated for mono-lithium TSs, ${ }^{9}$ (1753.0i and $1556.8 \mathrm{i} \mathrm{cm}{ }^{-1}$, respectively), which shows that the heavy atoms have less freedom of movement in the two-lithium aggregates. Consequently, the lower activation energy for TS-R, compared to TS-S, is responsible for the preferential protonation via TS-R.

Despite the difficulty of studying these chemical processes in solution, where different aggregates are assumed to exist simultaneously, the present study has provided new insights into the general mechanism of enantioselective protonation, and furthermore has highlighted the role played by lithium bromide in the formation of mixed dimers. 


\section{Enantioselective protonation: external quench}

Enantioselective protonation using the external quench strategy has received far less attention. This strategy involves the formation of a chiral enolate by complexation with a chiral ligand and its protonation by an external achiral proton source. The most significant work following this approach has been reported by Koga, ${ }^{17}$ who described the enantioselective protonation of tetralone-based enolates using a $\mathrm{C}_{2}$-symmetric tetramine as a chiral ligand and citric acid as an external proton donor. The reported stereocontrol was excellent with both stoichiometric and sub-stoichiometric amounts $(10 \%)$ of the chiral ligand.

In the course of our study on asymmetric protonation we also tested the possibility of applying aprotic sulfoxide derivatives $\mathbf{7}$ and $\mathbf{8}$ as chiral ligands of enolates that can be protonated in an asymmetric fashion by achiral proton sources. ${ }^{12}$ To this end, we prepared several sulfinyl pyridine derivatives and 1,3-bis-sulfoxides. Both types of compounds are readily obtainable in a pure chiral form from commercially available menthyl $p$-tolyl sulfinate. ${ }^{18,19}$ Our findings with this version of enantioselective protonation were not as relevant as those with the 2-sulfinyl alcohols. Only modest enantioselectivities were obtained despite the different variables tested to improve our results.

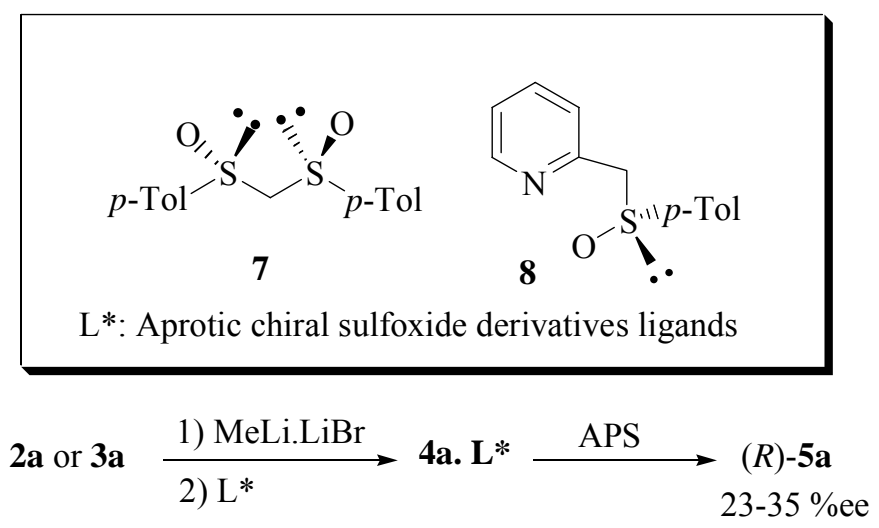

Scheme 3. External quench enantioselective protonation of lithium ketone enolates with aprotic sulfoxide derivatives.

\section{Catalytic enantioselective protonation}

In the past few years enantiocatalytic protonation has received significant attention and considerable effort has been devoted to the rational design of appropriate catalytic systems, although this aspect remains largely empirical. Despite the total recovery of the chiral protonating reagent in enantioselective protonation reactions, there could be clear advantages if sub-stoichiometric or catalytic quantities of the chiral proton source would be sufficient. The asymmetric protonation of metal enolates fundamentally occurs catalytically if a coexisting achiral proton source (HY) reacts faster with the deprotonated chiral proton source $\left(\mathrm{X}^{*}\right)$ than with the metal enolate (Schemes 4 and 5). 


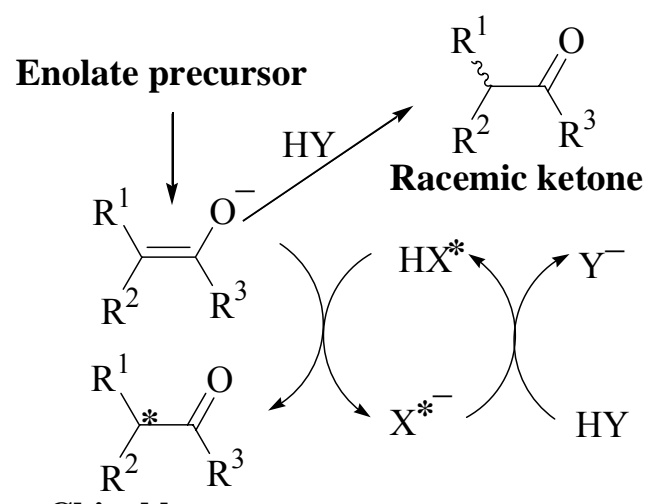

Chiral ketone

Scheme 4. Catalytic Enantioselective Protonation. (Protocol A).

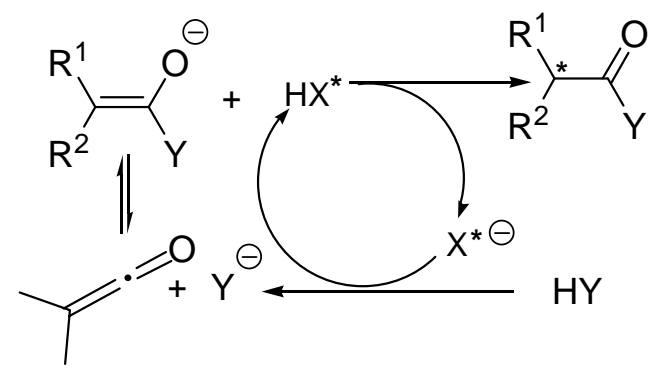

Scheme 5. Catalytic Enantioselective Protonation. (Protocol B).

Among the methods described for the internal quench catalytic enantioselective protonation of lithium enolates, two protocols can be distinguished based on the concentration of the enolate in the reaction medium. The first and more frequently described protocol involves a preformed enolate; i.e., all of the enolate is generated in the initial stage of the reaction (Protocol A) (Scheme 4). ${ }^{20}$ The second variant involves a transient enolate; i.e., the enolate is slowly and progressively generated during the reaction (Protocol B) (Scheme 5) ${ }^{21}$ In both variants, only a sub-stoichiometric (or catalytic) amount of a chiral protic compound is used to protonate the enolate, and subsequent regeneration of this chiral proton source (CPS) by the addition of a stoichiometric amount of an achiral proton source (APS) is required to lead the reaction to completion.

\section{Catalytic enantioselective protonation: the preformed enolate protocol}

In the previously described enantioselective protonation reactions with 2-sulfinyl alcohols and lithium enolates, optimal stereoselection was only achieved when the reagent ratio was 2.5-3:1 (alcohol:enolate). For the purpose of enolate generation, while both silyl enol ether 3a and enol acetate $2 \mathbf{a}$ can be used as precursors of enolate $\mathbf{4 a}$, we selected 3a because no additional base is formed in the medium, whereas with 2a an equivalent of lithium tert-butoxide is generated and then at least two equivalents of the chiral proton donor will be consumed. When enolate 4a 
generated by treating 3a with MeLi.LiBr (1.1 eq) was reacted with 3 eq. of chiral sulfinyl alcohol 1f at $-50^{\circ} \mathrm{C}$, ketone 4 was obtained with high enantioselectivity ( $89 \%$ ee). Conversely, when the amount of sulfinyl alcohol $\mathbf{1 f}$ was reduced to 1.2 eq., enantioselectivity was lowered to $78 \%{ }^{11 a}$ In this run, an additional $1.8 \mathrm{eq}$ were added before the temperature was allowed to increase to $0^{\circ} \mathrm{C}$, to preclude the eventual deprotonation of the chiral ketone by $\mathbf{1 f}-\mathrm{Li}$. Thus, the result indicates that more than $1.2 \mathrm{eq}$ are required to achieve the maximum ee. This finding may be a result of various causes: a low equilibrium constant for the complex $\mathbf{1 f}-\mathbf{4 a}$, the formation of complexes of type $(\mathbf{1 f})_{\mathrm{n}}-\mathbf{4 a}(\mathrm{n}>1)$ and/or the coordination of sulfinyl alcohol $\mathbf{1 f}$ with $\mathrm{LiBr}$

present in the reaction medium. To improve the stereoselection when a stoichiometric amount of chiral sulfinyl alcohol is used, we decided to try regeneration of the chiral proton donor by adding an achiral proton source (APS). Selection of the appropriate APS is related to its $\mathrm{pKa}$ value. Along these lines, Vedejs ${ }^{20 \mathrm{~d}}$ reported that the optimal $\mathrm{pKa}$ value for the APS should be near that of the chiral proton source, but greater enantioselection can be observed over a broad $\mathrm{pKa}$ range $(\Delta \mathrm{pKa} c a)$.

We selected 2,2,2-trifluoroethanol (TFE) as an APS because it falls within the range of $\mathrm{pKa}$ required and can be easily eliminated by simple evaporation, which facilitates purification of the chiral ketone. When enolate 4a was subjected to protonation with sulfinyl alcohol $\mathbf{1 f}$ (1.2 eq.) and TFE (1 eq.) was slowly added to the solution over $1.5 \mathrm{~h}$ (Table 5, entry 1), ketone 5a could be isolated with a high level of enantioselectivity (86\%). In this run, one additional equivalent of TFE was added before the temperature was allowed to increase to $0^{\circ} \mathrm{C}$ to avoid eventual racemization of the chiral ketone by the basic species in the medium. Variation of the time of addition of TFE (Table 5, entries 2 and 3) slightly affected the enantioselection achieved. If the chiral proton source can be reproduced in the reaction by a reprotonating achiral reagent, ketones can be prepared with optimal chemical and optical yield. Next, we tried to perform the reaction using sub-stoichiometric amounts of chiral sulfinyl alcohol 1f. As shown in Table 5, progressive reduction of the chiral sulfinyl alcohol $1 \mathbf{f}$ also led to a progressive decrease in the e.e. despite the time used for the addition of the stoichiometric amount of TFE. (Table 5, entries 4-8).

Next, we focused on identifying appropriate conditions for the catalytic enantioselective protonation of enolate 4a with sulfinyl alcohol 1f. As has been established by Fehr, ${ }^{20 b}$ the key to success in a catalytic cycle is to find an achiral proton source with higher reactivity toward the conjugate base of the chiral proton donor than to the enolate. For this purpose, $\mathrm{pK}_{\mathrm{a}}$ matching between the achiral proton source and the enolate and control of the concentration of the achiral proton donor are important variables to be considered. Thus, we carried out a series of runs using different achiral proton donors and modulated their concentrations in the reaction medium by varying the times of addition. Initially, we used $20 \%$ of chiral proton donor and a stoichiometric amount of achiral proton donor. 
Table 5. Asymmetric protonation of enolate $4 \mathrm{a}$ with stoichiometric and sub-stoichiometric amounts of sulfinyl alcohol $1 \mathrm{f}$

\begin{tabular}{|c|c|c|c|}
\hline Run & 1f (eq.) & TFE (eq.)/ Time (h) & e.r. \\
\hline 1 & $\begin{array}{c}1.2 \\
\mathrm{~b} \\
\mathrm{~d}\end{array}$ & $1.3 / 1.5$ & $93: 7$ \\
\hline 2 & $\begin{array}{c}1.2 \\
\mathrm{~b} \\
\mathrm{~d}\end{array}$ & $1.3 / 2.0$ & $90: 10$ \\
\hline 3 & $\begin{array}{c}1.2 \\
\mathrm{~b} \\
\mathrm{~d}\end{array}$ & $1.3 / 1.0$ & $90: 10$ \\
\hline 4 & $\begin{array}{c}1.0 \\
b \\
d\end{array}$ & $1.3 / 1.5$ & $91: 9$ \\
\hline 5 & $\begin{array}{c}0.8 \\
\mathrm{~b} \\
\mathrm{~d}\end{array}$ & $1.3 / 2.0$ & $87: 13$ \\
\hline 6 & $\begin{array}{c}0.8 \\
\mathrm{~b} \\
\mathrm{~d}\end{array}$ & $1.3 / 3.0$ & $88: 12$ \\
\hline 7 & $\begin{array}{c}0.4 \\
\mathrm{~b} \\
\mathrm{~d}\end{array}$ & $1.3 / 4.0$ & $81: 19$ \\
\hline 8 & 0.2 & $1.3 / 4.0$ & $77: 23^{c}$ \\
\hline
\end{tabular}


Table 6. Asymmetric protonation of enolate $4 \mathrm{a}$ with $20 \%$ of sulfinyl alcohol if

\begin{tabular}{|c|c|c|c|}
\hline Run & $\operatorname{APS}(1.3 \mathrm{eq}) / \mathrm{t}(\mathrm{h})$ & $\mathrm{pKa}^{\mathrm{a}}$ & e.r \\
\hline 1 & $\begin{array}{l}\text { 2,6-DFT/ } 4 \\
\mathrm{~b} \\
\mathrm{~d}\end{array}$ & 16.85 & $75: 25$ \\
\hline 2 & $\begin{array}{l}\mathrm{PhCH}_{2} \mathrm{CN} / 4 \\
\mathrm{~B} \\
\mathrm{D}\end{array}$ & 21.9 & $70: 30$ \\
\hline 3 & $\begin{array}{l}\mathrm{CF}_{3} \mathrm{CH}_{2} \mathrm{OH} / 4 \\
\mathrm{~B} \\
\text { D }\end{array}$ & 23.45 & $77: 23$ \\
\hline 4 & $\begin{array}{l}\mathrm{CH}_{3} \mathrm{CONH}_{2} / 4 \\
\text { B } \\
\text { D }\end{array}$ & 25.5 & 67.33 \\
\hline 5 & $\begin{array}{l}\mathrm{CH}_{3} \mathrm{CH}_{2} \mathrm{OH} / 4 \\
\mathrm{~B} \\
\text { D }\end{array}$ & 29.0 & $72: 28$ \\
\hline 6 & $\begin{array}{l}\mathrm{CF}_{3} \mathrm{CH}_{2} \mathrm{OH} / 2 \\
\mathrm{~B} \\
\text { D }\end{array}$ & 23.45 & $66: 34$ \\
\hline 7 & $\begin{array}{l}\mathrm{CH}_{3} \mathrm{CONH}_{2} / 2 \\
\mathrm{~B} \\
\text { D }\end{array}$ & 25.5 & $68: 32$ \\
\hline 8 & $\mathrm{ClCH}_{2} \mathrm{CH}_{2} \mathrm{OH} / 2$ & & $55: 45$ \\
\hline 9 & $t-\mathrm{BuOH} / 2$ & 32.2 & $70: 30$ \\
\hline 10 & $\mathrm{CF}_{3} \mathrm{CH}_{2} \mathrm{OH} / 6$ & 24.45 & $74: 26$ \\
\hline 11 & $\mathrm{CH}_{3} \mathrm{CONH}_{2} / 6$ & 25.5 & $74: 26^{\mathrm{c}}$ \\
\hline 12 & $\mathrm{CF}_{3} \mathrm{CH}_{2} \mathrm{OH} / 14$ & 23.45 & $73: 27$ \\
\hline
\end{tabular}

${ }^{\mathrm{a}}$ Data from reference 23 .

As shown in Table 6, despite the differences between the different achiral proton donors with regard to the $\mathrm{pKa}$ value, ${ }^{22}$ the type of atom that acts as a proton donor and the variable concentration in the medium, the corresponding ketones were obtained with similar e.e. in all of the runs.

Based on these findings, it is clear that the sulfinyl alcohol $\mathbf{1 f}$ is recycled but the rate is not enough to compete with the achiral proton source. At this point, we hypothesized that the failure in the catalytic cycle may be due to the coordination of sulfinyl alcohol 1f with the free (not associated with enolate) $\mathrm{LiBr}$ that is present in the medium. The concentration of free $\mathrm{LiBr}$ increases with time because it is produced after enolate protonation. Thus, in the advanced stages 
of the reaction, the concentration of $\mathrm{LiBr}$ exceeds the amounts of enolate and sulfinyl alcohol $\mathbf{1 f}$, and thus coordination of enolate with sulfinyl alcohol $\mathbf{1} \mathbf{f}$ is disfavored by competition with $\mathrm{LiBr}$ and as a consequence protonation of the enolate takes place by the achiral proton source. Attempts to eliminate this eventual coordination through the addition of some lithium ligands such as 12-crown-4, THF, and DME, did not have the desired effect, probably because these ligands can coordinate not only with $\mathrm{LiBr}$ but also with lithium enolate interfering with coordination of the chiral proton source and enantioselective protonation.

In conclusion, the catalytic enantioselective protonation of lithium ketone enolate 5a with sulfinyl alcohol 1f through the use of preformed enolate led to the corresponding chiral ketone with only moderate e.e. The failure of efficient facial discrimination when the sulfinyl alcohol is present in catalytic amounts may be related to a reversible proton transfer step. If so, we believe that the problems observed with the previously described procedure can be avoided by applying the transient enolate protocol.

\section{Catalytic enantioselective protonation: the transient enolate method}

We have recently designed an alternative approach to the catalytic enantioselective protonation with 2-sulfinyl alcohols in which enolate is slowly generated in the reaction medium. ${ }^{23}$ The method was designed to circumvent the limitations related to the preformed enolate approach, especially the reversibility of the proton transfer step as shown by the fact that a 2.5 -fold excess of protic compounds (chiral + achiral) versus enolate was needed to take the reaction to completion. Since only 0.4 equiv. of sulfinyl alcohol 1a were used, it is evident that would be impossible to maintain a low concentration of achiral protic compound with respect to the chiral one, which is crucial for achieving good stereoselection. Therefore, under these conditions the catalytic cycle can not compete with the unwanted protonation of the enolate by the APS and only moderate stereoselection can be achieved. Additionally, when the preformed enolate protocol is followed, at least in the initial stages of the reaction, the concentration of enolate exceeds that of the sulfinyl alcohol conjugate base (1a-Li), which may lead to undesired deprotonation of the APS by the enolate. It should be possible to control these two unfavorable aspects if the enolate is slowly generated in the reaction medium (the transient enolate protocol). We proposed a working hypothesis that, following this second alternative, the amount of enolate the achiral alcohol must be deprotonated by the sulfinyl alkoxide but not the enolate. The low concentration of enolate in the medium disfavors its unwanted competitive protonation by the achiral proton source. With these ideas in mind, we devised a catalytic cycle for the enantioselective protonation of cyclic ketone enolates by slow generation of the enolate in which an achiral alcohol plays two roles; i.e., regenerating the chiral proton source by proton transfer and generating the enolate through reaction of its conjugate base (alkoxide) with the appropriate enolate precursor. This method for the generation of enolates offers an additional advantage, since the alkoxide of the achiral proton source is transformed into a neutral compound, thus avoiding base accumulation in the medium and precluding the eventual racemization of the resulting chiral ketone. We found that enol trifluoroacetate derivative of 2-methyl tetralone $\mathbf{2 h}$ 
resulted an appropriate enolate precursor under the conditions required for the catalytic cycle. When enantioselective protonation of the lithium enolate of 2-methyl tetralone was performed according to the catalytic cycle depicted in scheme 6 moderate to good stereoselectivities were obtained depending on the structure of the alcohol used as APS. Among the different alcohols tested cyclohexanol yielded the higher asymmetric induction $(85 \%$ ee).

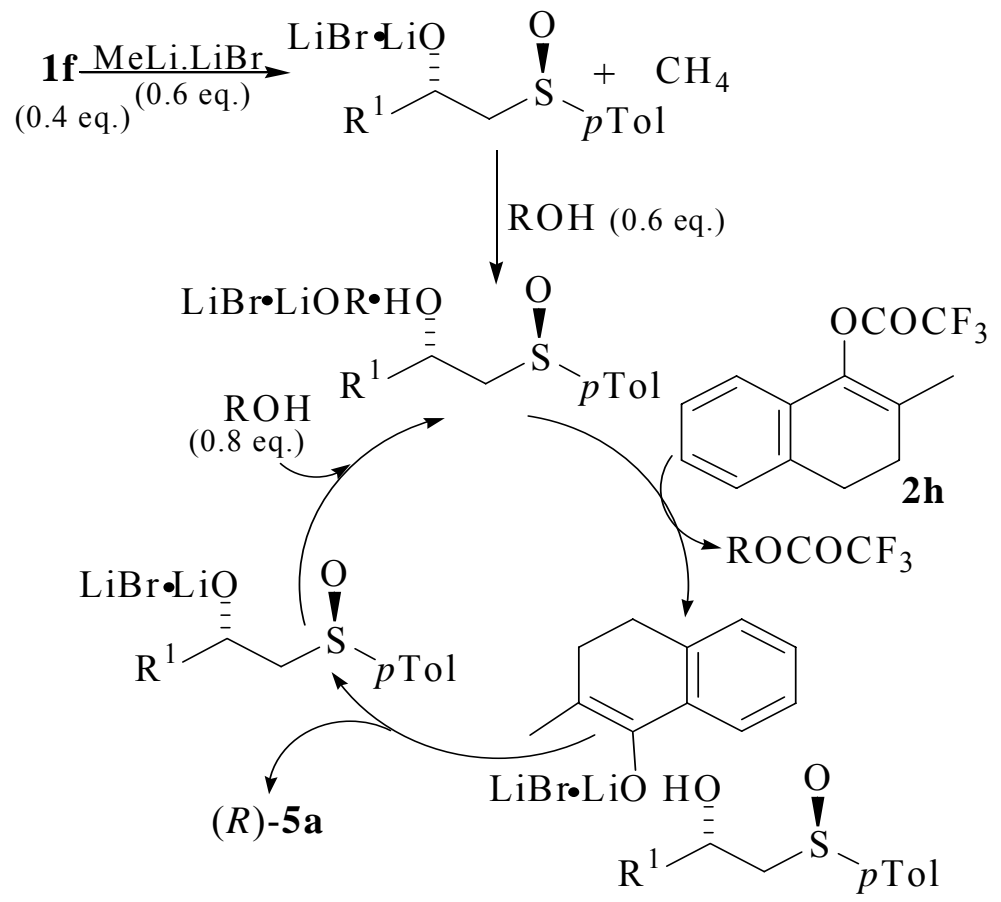

Scheme 6. Catalytic cycle of the enantioselective protonation with slow generation of the enolate.

\section{Summary and Outlook}

In conclusion, we have found that 2-sulfinyl alcohols are efficient protonating reagents of lithium tetralone-based enolates and cyclohexanone-based enolates. To achieve the highest enantioselectivity, the correct selection of parameters, such as the presence of additives and a suitable temperature, must be taken into account. Under the correct reaction conditions, enantioselectivities of up to $95 \%$ can be reached. A catalytic version of the reaction gave only moderate enantioselectivities using a preformed enolate, however the preliminary results indicate that the transient enolate strategy may actually give better results.

Although some insight was gained on the topic of enantioselective protonation in the 1990's, there are only a limited number of reported applications. The accumulation of more mechanistic information on the role of additives and the dynamic structure of enolates should contribute to the development of more general reagents for the enantioselective C-protonation of enolates. 


\section{References and Footnotes}

1. Reviews (a) Eames, J.; Weerasooriya, N. Tetrahedron: Asymmetry 2001, 12, 1. (b) Fehr, C. Angew. Chem. Int., Ed. 1996, 35, 2566. (c) Yanagisawa, A.; Yamamoto, $\mathrm{H}$ In Comprehensive Asymmetric Catalysis; Jacobsen, E.N.; Platz, A.; Yamamoto, H. Eds; Springer: Berlin, 1999; Vol. II, p 2566.

2. Vedejs, E.; Lee, N. J. Am. Chem. Soc. 1994, 116, 2175.

3. Fehr, C.; Chaptal-Gradoz, N.; Galindo, J. Chem. Eur. J. 2002, 8, 853. (b) Fehr, C.; Galindo, J. J. Am. Chem. Soc. 1988, 110, 6909. (c) Fehr, C.; Guntern, O. Helv. Chim. Acta 1992, 75, 1023.

4. Raymond, J.-C; Jahangiri, G. K.; Stoudt, C.; Lerner, R. A. J. Am. Chem. Soc. 1993, 115, 3909.

5. Reports after reviews (a) Carbery, D. R.; Donohoe, T. J. Chem. Comm. 2004, 722. (b) Navarre, L.; Darses, S.; Genet, J. P. Angew. Chem., Int. Ed. 2004, 43, 719. (c) Hamashima, Y.; Somei, H.; Shimura, Y.; Tamura, T.; Sodeoka, M. Org. Lett. 2004, 6, 1861. (d) Kim, B. M.; Kim, W.; Im, K. Y.; Park, J. K. J. Org. Chem. 2004, 69, 5104. (e) Fehr, C.; Galindo, J.; Farris, I.; Cuenca A. Helv. Chim. Acta 2004, 87, 1737. (f) Belokon, Y. N.; Harutyunyan, S.; Vorontsov, E. V.; Peregudov, A. S.; Chrustalev, V. N.; Kochetkov, K. A.; Pripadchev, D.; Salvan, A. S.; Beck, A. K.; Seebach, D. ARKIVOC 2004, (iii), 132. (g) Hanquet, G.; Colobert, F.; Lanners, S.; Soladie, G. ARKIVOC 2003, (vii), 328. (h) Muňoz-Muniz, O.; Juaristi, E. Tetrahedron Lett. 2003, 44, 2023. (i) Futasugi, K.; Yanagisawa, A.; Yamamoto, H. Chem. Comm. 2003, 566. (j) Bach, T.; Grosch, B.; Strassner, T.; Herdtweck, E. J. Org. Chem. 2003, 68, 1107. (k) Clericuzio, M.; Degani, I.; Dughera, S.; Fochi, R. Tetrahedron: Asymmetry 2003, 14, 119. (1) Roy, O.; Riahi A.; Henin, F.; Muzart, J. Eur. J. Org. Chem. 2002, 3986. (m) Yanagisawa. A.; Matsuzaki, Y.; Yamamoto, H. Synlett 2001, 1855.

6. Reports after reviews (a) Ohtsuka, Y.; Ikeno, T.; Yamamada, T. Tetrahedron: Asymmetry 2003, 14, 967. (b) Flinois, K.; Yuan, Y.; Bastide, C.; Harrison-Marchand, A.; Maddaluno, J. Tetrahedron 2002, 58, 4707.

7. (a) Yanagisawa, A.; Kuribayashi, T.; Kikuchi, T.; Yamamoto, H. Angew. Chem., Int. Ed. 1994, 33, 107. (b) Yanagisawa A.; Kikuchi, T.; Kuribayashi, T.; Yamamoto, H. Tetrahedron 1998, 54, 10253. (c) Yanagisawa, A.; Kikuchi, T.; Kuribayashi, T.; Yamamoto, H. Synlett 1998, 174. (d) Nakamura, Y.; Takeuchi, S.; Ohgo, Y.; Yamaoka, M.; Yoshida, A.; Mikami, K. Tetrahedron 1999, 55, 4595. (e) Asensio, G.; Cuenca, A.; Rodriguez, N.; Medio-Simon, M. Tetrahedron: Asymmetry 2003, 14, 3851. (f) Kosugi, H.; Hoshino, K.; Uga, H. Tetrahedron Lett. 1997, 38, 6861.

8. Duhamel, L.; Plaquevent, J.-C. J. Am. Chem. Soc. 1978, 100, 7415.

9. Asensio, G.; Aleman, P.A.; Domingo, L.R.; Medio-Simon, M. Tetrahedron Lett 1998, 39, 3277.

10. Asensio, G.; Aleman, P.A.; Gil, J.; Domingo, L.R.; Medio-Simon, M. J. Org. Chem. 1998, 63, 9342. 
11. (a) Asensio, G.; Gil, J.; Alemán, P. A.; Medio-Simón, M. Tetrahedron: Asymmetry 2001, 12, 1359. (b) Aleman, P. Ph.D. Thesis, University of Valencia, 1998.

12. Cuenca, A., Ph.D. Thesis, University of Valencia, 2001.

13. Asensio, G.; Aleman, P.A.; Cuenca, A.; Gil, J.; Medio-Simon, M. Tetrahedron: Asymmetry 1998, 9, 4073.

14. Cavelier, F.; Gomez, S.; Jacquier, R.; Verducci, J. Tetrahedron Lett. 1994, 35, 2891.

15. Asensio, G.; Cuenca, A.; Gavina, P.; Medio-Simon, M. Tetrahedron Lett. 1999, 40, 3939.

16. Seebach, D. Angew. Chem., Int. Ed. 1988, 27, 1624.

17. Yamashita, Y.; Emura, Y.; Odashima, K.; Koga, K. Tetrahedron Lett. 2000, 41, 209.

18. (a) Kagan, H.B.; Baldenius, K. Tetrahedron: Asymmetry 1990, 1, 597. (b) Furukawa, N.; Hosono, E.; Fujihara, H.; Ogawa, S. Bull. Chem. Soc. Jpn. 1990, 63, 461.

19. (a) Kunieda, N.; Nokami, J.; Kinoshita, M. Bull. Chem. Soc. Jpn. 1976, 49, 256. (b) Khiar, N.; Fernandez, I.; Alcudia, F. Tetrahedron Lett. 1993, 34, 123.

20. Catalytic Internal Quench: (a) Fehr, C.; Stempf, I.; Galindo, J. Angew. Chem., Int. Ed. 1993, 32, 1044. (b) Fehr, C.; Galindo, J. Angew. Chem. Int., Ed. 1994, 33, 1888. (c) Fehr, C.; Galindo, J. Helv. Chim. Acta. 1995, 78, 539. (d) Vedejs, E.; Kruger, A.W. J. Org. Chem. 1998, 63, 2792. (e) Vedejs, E.; Kruger, A.W.; Lee, N.; Sakata, S. T.; Stec, M.; Suna, E. J. Am. Chem. Soc. 2000, 122, 4602. (f) Yanagisawa A.; Watanabe, T.; Kikuchi, T; Yamamoto, H. J. Org. Chem. 2000, 65, 2979. (g) Yanagisawa, A.; Watanabe, T.; Kikuchi, T; Yamamoto, H. J. Am. Chem. Soc. 2000, 122, 8120. (h) Yanagisawa A.; Watanabe, T.; Kikuchi, T.; Yamamoto, H. J. Am. Chem. Soc. 1996, 118, 12854. (i) Watanabe, T.; Kuribayashi, T.; Yamamoto, H. Synlett 1995, 372. (j) Muzart, J.; Hénin, F.; Aboulhoda, S. J. Tetrahedron: Asymmetry 1997, 8, 381. (k) Nakamura, Y.; Takeuchi, S.; Ohira, A.; Ohgo, Y. Tetrahedron Lett. 1996, 37, 2805. (1) Takeuchi, S.; Nakamura, Y.; Ohgo, Y.; Curran, D. P. Tetrahedron Lett. 1998, 39, 8691.

21. Catalytic External Quench: (a) Nishimura, K.; Ono, M.; Nagaoka, Y.; Tomioka, K. Angew. Chem. Int. Ed. 2001, 40, 440. (b) Emori, E.; Arai, T.; Sasai, H.; Shibasaki, M. J. Am. Chem. Soc. 1998, 120, 4043. (c) Sugiura, M.; Nakai, T. Angew. Chem., Int. Ed. 1997, 36, 2366. (d) Riviere, P.; Koga, K. Tetrahedron Lett. 1997, 43, 7589.

22. Bordwell, F.G. Acc. Chem. Res. 1988, 21, 456.

23. Gil, J.; Medio-Simon, M.; Mancha, G.; Asensio, G. Eur. J. Org. Chem. 2004, in press. 